\title{
Cavalerie (La)
}

Menhir de Montrepos

\section{(2) OpenEdition \\ Journals}

Édition électronique

URL : http://journals.openedition.org/adlfi/10456

ISSN : 2114-0502

Éditeur

Ministère de la culture

\section{Référence électronique}

"Cavalerie (La)», ADLFI. Archéologie de la France - Informations [En ligne], Midi-Pyrénées, mis en ligne le 01 mars 1997, consulté le 03 mai 2019. URL : http://journals.openedition.org/adlfi/10456

Ce document a été généré automatiquement le 3 mai 2019.

(c) Ministère de la Culture et de la Communication, CNRS 


\title{
Cavalerie (La)
}

\author{
Menhir de Montrepos
}

\section{Identifiant de l'opération archéologique :}

Date de l'opération : 1989 (SU)

Inventeur(s) : Serres J.-P

1 Le menhir de Montrepos fut découvert en 1960 par J.-P. Serres sur le plateau du Larzac. Ses dimensions sont les suivantes : longueur, $3 \mathrm{~m}$; largeur, $0,60 \mathrm{~m}$ à $0,80 \mathrm{~m}$; épaisseur, $0,50 \mathrm{~m}$. La roche qui le constitue est une dolomie, absente dans le substratum sur lequel fut érigé le monument. Le fait qu'il ait été couché depuis longtemps a entrainé une forte corrosion de l'une de ses faces principales. Cette même face est, par ailleurs, creusée d'une profonde cupule, d'une large cuvette et d'une rigole. La fouille présentait un triple objectif : retrouver la trace d'éventuelles structures ayant entouré le monument, déceler les vestiges contemporains de l'érection ou résultant d'un culte possible, dégager la fosse dans laquelle sa base avait été placée. Le redressement du menhir sur place était l'aboutissement de cette opération.

2 Avec le concours des techniciens du Camp militaire du Larzac, dotés du matériel et des moyens mécaniques adéquats, la fouille s'est révélée positive avec la mise en évidence d'une fosse de $0,80 \mathrm{~m}$ de large et près de $0,70 \mathrm{~m}$ de profondeur contre l'une des extrémités de la dalle (Fig. $n^{\circ} 1$ : Menhir en cours de fouille (la fosse aménagée pour recevoir le mégalithe est au premier plan)). Des observations fort pertinentes ont été consignées par J.-P. Serres et ses collaborateurs sur l'adaptation des techniques utilisées par les hommes préhistoriques face aux contraintes naturelles dues à la diversité lithologique du substratum.

3 Le creusement a été amorcé le long d'une fissure sous le côté est du mégalithe: pratiquement à la surface du sol, deux outils particulièrement intéressants ont été découverts. L'un d'eux est un bloc de basalte à peine dégrossi par retouches inverses, lui conférant une extrémité acérée. L'autre outil, également en basalte, est nettement plus élaboré : un tranchant semblable à celui d'une hache polie fut obtenu par polissage. Long 
de $28 \mathrm{~cm}$, cet outil pèse près de $10 \mathrm{~kg}$. Après avoir servi probablement au creusement de la fosse, ils ont été abandonnés sur place.

4 Le plus proche pointement basaltique connu se trouve à $2,5 \mathrm{~km}$ du lieu d'érection. Cette opération à valeur d'exemple aussi bien pour la richesse des observations scientifiques que pour la protection du monument.

\section{ANNEXES}

Fig. $n^{\circ} 1$ : Menhir en cours de fouille (la fosse aménagée pour recevoir le mégalithe est au premier plan)

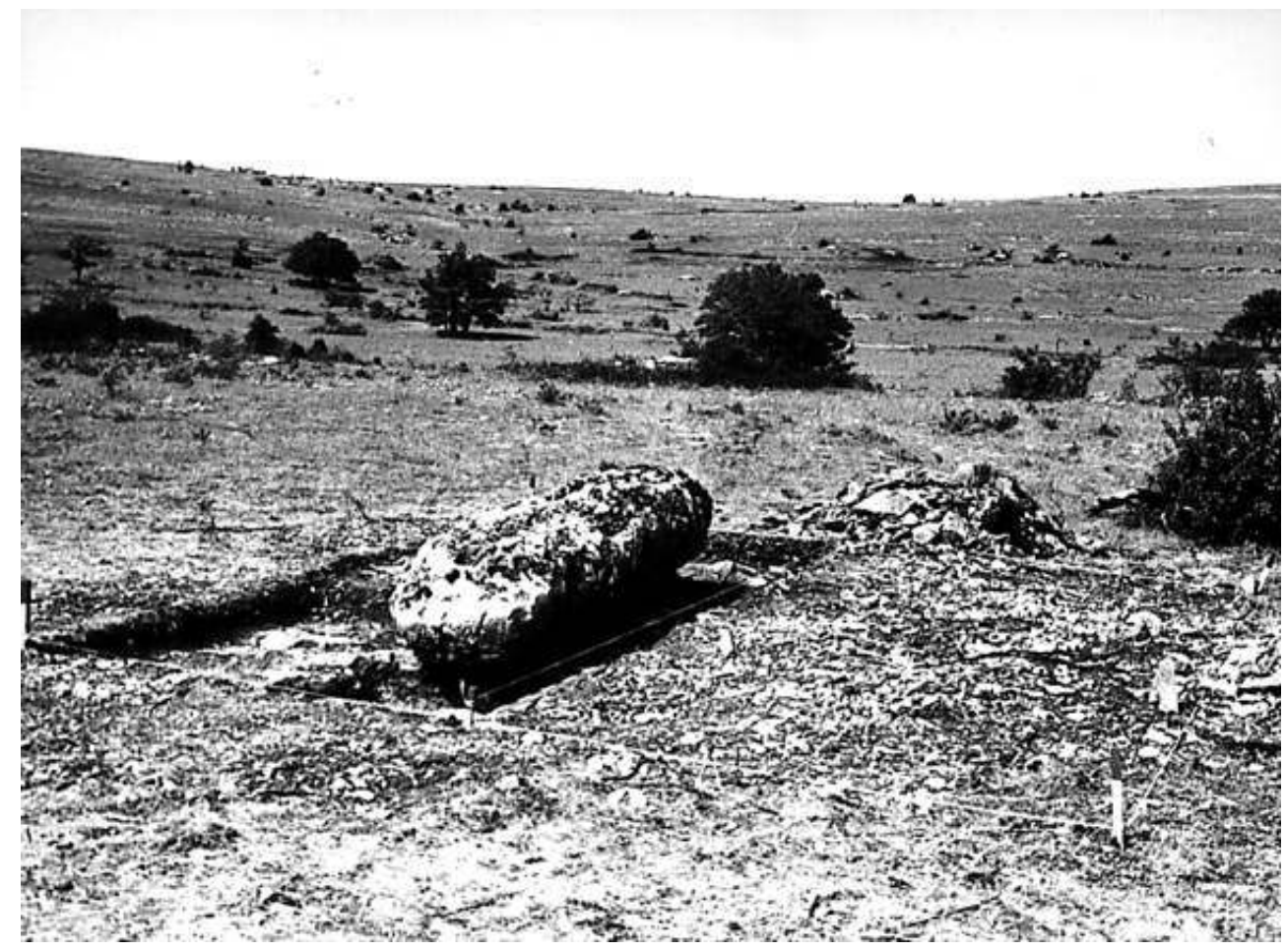

Auteur(s) : Serres, J.-P. Crédits : GI 1997 ; ADLFI 1998 (1989)

\section{INDEX}

Index chronologique : Néolithique

Index géographique : Midi-Pyrénées, Aveyron (12), Cavalerie

operation Sauvetage urgent (SU) 